Sex work and health

\section{Short term interventions are not enough}

\section{H Ward}

\section{Sex work and health in the free market}

T he introduction of market capitalism into the countries of the former Soviet Union, eastern Europe, and China has been associated with a social revolution. This is reflected in changes to employment, the family, mobility, state institutions, and culture. Many people face a precarious economic situation following the closure of state industries, the ending of food subsidies and declining welfare provision. Women have been harshly affected and sex inequalities have increased. Eastern Europe is the only area of the world where there has been a recent decline in the proportion of women in formal employment, ${ }^{1}$ and a decline in the proportion of girls going to school in two thirds of the countries. With these economic conditions it is inevitable that there will be an expansion in the informal economy, including trade in sex as a temporary survival strategy or, for some, a medium term strategy out of poverty.

These sex workers are vulnerable to HIV, STIs, and other risks of sex work related to violence and exploitation. The risks are heightened by the increase in sexually transmitted infections in many of these states. ${ }^{34}$ Shaojun $\mathrm{Ma}$ and colleagues in this issue of STI (p 110) report the impact of a short term intervention for sex workers in Guangzou, China. ${ }^{5}$ The team provided screening and treatment for infections along with health promotion and condom distribution. Reported risk behaviours declined along with the incidence of bacterial STIs. This confirms once again that the provision of services and advice to sex workers is very effective. While this has not previously been reported in China, the key message is not new and has been shown in a wide variety of settings. ${ }^{6-8}$ However, this intervention was short term, and it is equally clear that sustained action is necessary if the changes are to be maintained. ${ }^{9}$ Sex workers are very mobile within and between countries, new women enter the business constantly, and therefore ongoing programmes are needed.

What then are the obstacles to sustained effective interventions? The fundamental obstacle is the hypocrisy that surrounds sex work. In most countries sex work is not legal, workers are repressed, stigmatised, and denied human rights. In China, sex work is illegal, and workers are arrested and detained for "re-education." This is not only an abuse of human rights, it is also going to facilitate the spread of HIV and other infections in the population. But China is not alone. In the United Kingdom, sex workers and clients are arrested and fined. In Sweden, clients are arrested and "re-educated." In the United States sex workers are arrested and imprisoned. This repression is an obstacle to health and safety.

\section{The fundamental} obstacle ... to effective interventions .... is the hypocrisy that surrounds sex
work

In contrast, where sex work is legalfor example, in New South Wales, Australia, workers have been able to insist on health and safety policies that protect themselves, their clients, and new entrants into the business. ${ }^{10}$ Brothels have policies on condom use, access to health care is guaranteed, and workers have recourse to the law if they are abused and exploited. However, where sex work is not legal but criminalised, more pressure is placed on the individual sex worker and client to determine whether condom use occurs, and in many places this cannot happen. Condoms may not be available or be too expensive. Sex workers may lack the knowledge, the negotiating skills, or control to insist on condom use. Sex workers who are being abused and exploited, who are underage, or who are working against their will are unable and generally unwilling to seek help for fear of being turned into criminals.

Where sex work occurs without adequate safety, the consequences can be devastating, particularly in the early phase of an epidemic. In sub-Saharan Africa, sex workers were extremely vulnerable to HIV infection because of lack of safety in the early 1980s. Once the prevalence of infection in the wider population rises above a certain level, it is more difficult for limited increases in condom use to protect individuals and the broader population.

The sex industry is growing, fuelled on the one hand by globalisation and the free market increasing the "supply" of potential workers, and on the other by massive demand. In London, for example, $9 \%$ of men have paid for sex in the last 5 years, compared with 5\% 10 years ago. ${ }^{11}$ Prostitution is not going to go away so we should try to shift attention from idealist attempts to abolish it towards practical efforts to make it safe. We know what kind of health interventions are effective, and that they need to be sustained, not short term. ${ }^{12}$ We also know that decriminalisation is a key step in preventing epidemics of STI and widespread exploitation. In contrast, there are no published data supporting abolitionist policies as a way of promoting health and safety. Sex workers across the world are organising themselves for rights, an end to brutal oppression and exploitation, for quality health care, and for training and support for those who wish to leave the industry. ${ }^{13}$ The International Labour Organisation has correctly called for sex work to be recognised and for workers to be given rights as the best way of ending exploitation ${ }^{14}$ and, we should add, promoting health.

Sex Transm Infect 2002;78:80-81

\section{Author's affiliations}

H Ward, Department of Epidemiology and Public Health, Imperial College School of Medicine, St Mary's Campus, Norfolk Place, London W2 1PG, UK; h.ward@ic.ac.uk

\section{REFERENCES}

1 United Nations Development Fund for Women. Progress of the world's women 2000. Geneva: UNIFEM Biennial Report, 2000: http://www.un.org/Depts/unsd/ ww2000/overview.htm

2 World Bank. Engendering development-through gender equality in rights, resources and voice. Washington DC: World Bank/Oxford University Press, 2001.

3 Tichonova L, Borisenko K, Ward H, et al. Epidemics of syphilis in the Russian Federation: trends, origins and priorities for control. Lancet 1997; 350:213-13

4 Chen XS, Gong XD, Liang GJ, et al. Epidemiologic trend of sexually transmitted disease in China. Sex Transm Dis 2000;27:138-142

5 Ma S, Dukers NHTM, van den Hoek A, et al. Decreasing STD incidence and increasing condom use among Chinese sex workers following a short term intervention: a prospective cohort study. Sex Transm Inf 2002:78: 110-14.

6 Laga M, Alary M, Nzila N, et al. Condom promotion, sexually transmitted diseases treatment and the declining incidence of HIV-1 infection in female Zairian sex workers. Lancet 1994:344:246-8.

7 Asamoah-Adu A, Weir S, Pappoe M, et al. Evaluation of a targeted AIDS prevention intervention to increase condom use among prostitutes in Ghana. AIDS 1994;8:239-46.

8 Ward H, Day S, Weber JN. Risky business: health and safety in the sex industry over a 
nine year period. Sex Transm Inf 1999:75: 340-3

9 Kilmarx PH, Palanuvej T, Limpakarnjanarat $\mathrm{K}$, et al. Seroprevalence of HIV among female sex workers in Bangkok: evidence of ongoing infection risk after the "100\% condom program" was implemented. J Acquir Immune Def Syndr 1999:21:313-6.

10 Miles A. The sex industry legal kit for service providers and regulators. New South Wales: compiled by Sex Workers Outreach Project, 2000 (http://www.swop.org.au/ ressilk2.html, accessed 14 Febuary 2002)

11 Johnson AM, Mercer CH, Erens B, et al. Sexual behaviour in Britain: partnerships, practices, and HIV risk behaviours. Lancet 2001;358: 1835-42

12 European Network for HIV/STD

Prevention in prostitution

(Europap/Tampep). Hustling for health: developing services for sex workers in Europe. London: Imperial College, 1999.

13 International Network of Sex Work Projects (http://www.walnet.org/nswp)

14 Lim LL, ed. The sex sector: the economic and social bases of prostitution in Southeast Asia. Geneva: International Labour Organisation, 1998. See related press release (http://www.ilo.org/public/english/bureau/ inf/pr/1998/31.htm, accessed 14 February 2002)

\section{Revised UK national guidelines on sexually transmitted infections and closely related conditions 2002}

\section{R FitzGerald, I Ahmed-Jushuf, K W Radcliffe, G Rooney, J Welch, JD Wilson}

\section{Updating and improvements continue}

7 his month sees the final ratification of the revised UK national specialty guidelines, first published in Sexually Transmitted Infections in 1999. ${ }^{1}$ We trust they will continue be widely used to underpin best practice in genitourinary medicine. They are available to all via the websites of the UK specialist organisations (www.mssvd.org.uk and www. agum.org.uk) and are also on the database of the Royal College of Physicians Clinical Effectiveness and Evaluation Unit (CEEU) (www.rpclondon.ac.uk/ college/ceeu/ceeu_guidelinesdb.asp) and the National Guidelines Clearing House, Washington (www.guidelines.gov). The guidelines are commissioned by the Clinical Effectiveness Group (CEG), set up jointly by the Medical Society for the Study of Venereal Diseases and the Association for Genitourinary Medicine. The revision process commenced in 2000 with authors being invited to modify and update their 1999 guidelines. These revised versions were posted on the website for a 3 month period and comments invited. The CEG and the authors concerned considered all suggestions and agreed any modifications to be made. The major considerations throughout were clarity and support by published evidence. The successful outcome is a tribute to collaboration within the specialty as a whole but we are particularly grateful to the authors, writing groups, and webmasters for generously giving their time and expertise. The substantive changes are listed below. There have also been minor changes to the wording of most guidelines to make them clearer.

\section{URETHRITIS \\ Chlamydia}

Guidance is given on use of enzyme linked immunoassay tests (EIA) indicating that indeterminate results should be confirmed by a nucleic acid amplification test and that EIAs are not suitable for rectal or pharyngeal testing. The value of health advisers in partner notification is emphasised.

\section{Non-gonococcal urethritis (NGU)}

More specific data are given on the role of ureaplasmas and Mycoplasma genitalium in aetiology, now stated to cause $10-20 \%$ of acute cases and to be important in chronic NGU. It is suggested that partner notification information is obtained at the initial clinic visit and that follow up after treatment requires microscopy only if the patient has symptoms or signs of discharge.

\section{Gonorrhoea}

Increasing evidence of resistance to ciprofloxacin is noted, but it is still recommended as first line therapy; there have been no clinical trials of new licensed antigonococcal agents in the past 2 years.

\section{VAGINAL DISCHARGE}

\section{Bacterial vaginosis (BV)}

A variety of criteria for microscopic diagnosis are given. Further findings on the association between $\mathrm{BV}$ and preterm labour are reviewed with the conclusion that current evidence still does not support routine screening and treatment. Screening and treatment of BV before termination of pregnancy is recommended. One study has shown an association between BV and NGU in the male partner.

\section{Candidiasis}

The references and grading of evidence have been updated.

\section{Trichomoniasis}

The section on regimens for use in treatment failure has been altered. The references have been updated, including one linking trichomoniasis with transmission of HIV.

\section{GENITAL ULCERATION Genital herpes (GH)}

Data are given on the sensitivity and specificity of type specific serology and the use of these tests in diagnostic and screening (pregnancy) settings. For pregnancy, there is a reminder that aciclovir is unlicensed although considerable support for its use exists. For GH in late pregnancy the importance of trying to establish whether the episode is a first one is emphasised. There is a more detailed discussion of the role and content of counselling, and more data on natural history. The Tzanck test is removed from diagnostic techniques.

\section{Early syphilis}

There is now a description of the differential diagnosis of the primary lesion, and of non-syphilitic causes of positive treponemal serology. The use of EIA and PCR tests in diagnosis and screening is discussed. Regular screening for syphilis is recommended when there is an outbreak. For penicillin treatment the recommended duration is shortened to 10 days. Instructions are given on Jenacillin as a source of procaine penicillin. For non-penicillin treatments, tetracycline is no longer recommended, the use of doxycycline is discussed more fully, and more data are given on experience with ceftriaxone and azithromycin. Treatment regimens are suggested for incubating syphilis and for epidemiological treatment. In pregnancy it is recommended that there is no need to retreat women for syphilis already treated in a previous pregnancy. In congenital cases follow up should be for 
a minimum of 1 year, and the importance of screening siblings and parents in cases diagnosed after infancy is emphasised. Auditable outcome measures now include figures for the outcome of treatment and contact tracing.

\section{Late syphilis}

Tests and treatments are altered as for early syphilis. Penicillin regimens are shortened from 17-21 days to 17 days. All drug regimens are also now tabulated at the end of the guideline and there are appendices on penicillin desensitisation and skin testing. Physical examination in cases of late syphilis is outlined. There are suggestions on the use of TPHA tests on CSF in diagnosing neurosyphilis. In patients who do not have a CSF examination, treatment need not necessarily be as for neurosyphilis. Benzyl penicillin is described as being able to prevent progression to neurosyphilis despite not usually producing treponemicidal levels in CSF.

Donovanosis (granuloma inguinale) The causative organism has been redesignated Klebsiella granulomatis. Encouraging results with azithromycin are highlighted.

\section{Lymphogranuloma venereum}

Few new data here because of its continuing rarity in industrialised countries; molecular diagnostic tests have now been used successfully.

\section{Chancroid}

Diagnostic methods have been updated to include reports on molecular techniques. Single dose ciprofloxacin is now thought to be an effective treatment in HIV positive individuals.

\section{SYSTEMIC PRESENTATIONS AND COMPLICATIONS \\ Prostatitis}

The guidelines point out that the lower urinary tract localisation procedure is not often used in a clinical practice, and even when used it may not alter patient management. Data are given on studies of terazisine and quercetin in chronic prostatitis syndromes. The National Institutes for Health chronic prostatitis symptom index is suggested as an outcome measure.

\section{Epididymo-orchitis}

Behçet's disease and amiodarone are now included in the aetiology. For cases caused by enteric organisms, ciprofloxacin has been added to the recommended treatment.
Pelvic infection and perihepatitis More evidence is given for recommended treatment regimens and clarification of which regimens are suitable for outpatient and inpatient use. Some discussion of whether to remove intrauterine contraceptive devices in severe PID.

\section{Hepatitides A, B, and C}

Active research continues in this field and there are many changes in epidemiology and treatment. Hepatitis A: vaccination is now recommended for homosexual men under specific circumstances - that is, in areas of high prevalence among the homosexual population, such as central London. Hepatitis B: guidelines on treatment have been updated including information on new agents; flow charts are shown for the use of anti-HBc and HBs antibodies when screening. New information is given about the efficacy of hepatitis $\mathrm{B}$ vaccine with recommendations that boosters may not be required for 15 years after successful vaccination. Hepatitis $C$ : many changes, including updated information on diagnosis, prognosis, and treatment.

\section{Sexually acquired reactive arthritis}

No significant changes to aetiology, clinical features, or diagnosis. Latest data are given on use of antibiotic therapy, with recommendations unchanged. Updated information given on treatment in pregnancy and breastfeeding. Some new details given on the role of intra-articular steroids and on effects of sulphasalazine.

\section{MISCELLANEOUS}

\section{Anogenital warts}

The extent of subclinical wart virus infection is emphasised. Presentations listed now include bleeding from anus and urethra, and distorted urinary flow. On management, the evidence base to compare and chose treatments is acknowledged to be weak; some agents are commonly used outside their licensed indications. 5-Fluorouracil is no longer recommended for meatal warts. Podophyllin is no longer recommended for internal lesions, and is felt to have inferior efficacy to podophyllotoxin; it has a theoretical risk of oncogenicity but it is noted that this has not been observed in humans.

\section{Molluscum contagiosum, scabies Changes in some references only.}

\section{Pediculosis}

No changes.

\section{Sexual assault}

References updated.
Balanitis

References updated.

\section{THE FUTURE}

These guidelines are not a culmination but one step in a continuing process. The CEG is happy to receive comments and suggestions supported by appropriate references at any time, and will review them with the authors of the next revision. By this stage there will have been changes in the way in which the guidelines are developed. The Royal College of Physicians via its CEEU has recently endorsed the Appraisal of Guideline Research and Evaluation (AGREE) instrument ${ }^{2}$ as its framework for assessing guidelines. It covers the scope and purpose of the guidelines, stakeholder involvement, rigour of development, clarity and presentation, applicability, and editorial independence. The CEG will use this instrument in future. We also intend to keep abreast of and apply any developments in knowledge about what makes guidelines effective in modifying medical practice, a crucial issue and one which is still strikingly under-researched.

The current guidelines provide a considered summary of the evidence in each area. They are not a set of instructions but rather are a useful tool to apply to the infinite range of clinical presentations our patients provide us with. They are written for UK clinicians having at their disposal the full range of diagnostic methods and treatments of GUM clinics. If the intentions of the sexual health strategy $^{3}$ come about then an increasing amount of sexual health care will be done in general practice. This may require a very different set of guidelines in the future, and the work of a wider group.

Sex Transm Infect 2002;78:81-82

\section{Authors' affiliations}

M R FitzGerald, Genitourinary Medicine Department, Musgrove Park Hospital, Taunton, Somerset TÁl 5DA, UK

I Ahmed-Jushuf, Nottingham City Hospital K W Radcliffe, Whittall Street Clinic, Birmingham

G Rooney, Princess Margaret Hospital, Swindon

J Welch, King's College Hospital, London J D Wilson, Leeds General Infirmary

Correspondence to: Dr FitzGerald; med@tst.nhs.uk

\section{REFERENCES}

1 K Radcliffe, I Ahmed-Jushuf, F Cowan, et al. 1999 UK national guidelines on sexually transmitted infections and closely related conditions. Sex Transm Inf 1999;75(suppl 1).

2 The Agree Collaboration. Appraisal of guidelines for research and evaluation (AGREE) instrument.

Www.agreecollaboration.org

3 The national strategy for sexual health and HIV. July 2001: www.doh.gov.uk/jointunit/ iip.htm 